\title{
PLATONISMO E ARISTOTELISMO NO SÉCULO XII (III).
}

\section{RUY AFONSO DA COSTA NUNES}

Professor-assistente do Setor de Filosofia e História da żducaçá. Departamento de Educação da Faculdade de Filosofia, Ciências e Letras da Untversidade de São Paulo. .

(Conclusão) .

CAPITULO IV.

\section{JOÃO DE SALISBURY E O ARISTOTELISMO (119) .}

No primeiro capítulo tive a oportunidade de focalizar a maneira como João de Salisbury considerava Aristóteles em relação a Platão. Vou proceder agora a uma análise de alguns passos do Metalogicus nos quais o autor se manifesta a propósito da questão dos Universais e dos livros do Organon que vieram a constituir a Logica Nova. Com isso pretendo apresentar uma ilustração do aristotelismo no século XII, sem que seja minha intenção pôr em relêvo tôdas as referências do Saresberiense à lógica e a Aristóteles. De início, acho conveniente acompanhar o autor em seu depoimento autobiográfico a respeito dos próprios estudos, pois isso permitir-nos-á apreciar o processo da formação aristotélica pelo qual êle passou sob a direção de vários mestres em Paris e em Chartres (120).

De acôrdo com os aristotélicos, o sumo bem para o homem consiste no conhecimento da verdade. Daí terem êles procedido à inves-

(119) . - Não pude ter acesso à famosa edição do Metalógico feita por Webb. Além do texto que figura na Patrologia Latina de Migne, pude entretanto, consultar a excelente traduçâo para o inglês devida a MacGarry.

(120) . - As informaçōes de Salisbury, que passo a analisar, encontram-se principalmente no Livro II do Metalogicus. Além de imbuir-se dos princípios da Logica Vetus com seus mestres de Paris e de Chartres, êle se beneflciou do ensino de aristotélicos, como Abelardo e Adão da Ponte Pequena, assim como, mais tarde, através de suas viagens a Itália, se familiarizou com a Logica Nova. 
tigação da natureza das coisas, a fim de determinar o que deve ser evitado como mal, desprezado como inútil, buscado como bem, preferido como melhor, assim como procuraram determinar o que é considerado como bem ou mal, conforme as circunstâncias. Foi dêsse modo que surgiram as duas partes da filosofia: a natural e a moral, ou física e ética. Acontece, porém, que a inabilidade no raciocínio levava os homens a cometerem muitos absurdos, a formularem graves despautérios. Daí impor-se como recessidade a criação de uma ciência que estabelecesse distinções entre palavras e significados e que concorresse para dissipar a neblina das falácias. Era conveniente a constituição de uma ciência que servisse para o homem distinguir entre a verdade e a falsidade dos juízos, para assegurar o raciocínio correto, válido, para distinguir entre um argumento verossimil e um sofístico. De outra forma, quem raciocina não poderia dispor de critérios para a orientaçã̃o do pensamento com vistas à consecução da verdade.

Diz Salisbury que segundo Apuleio, Santo Agostinho e Santo 1sidoro, Platão teria aperfeiçoado a filosofia ao acrescentar a lógica à física, desenvolvida por Pitágoras, e à ética ensinada por Isócrates. Platão, entretanto, não desenvolveu a arte nem formulou a ciência do raciocínio, limitando se ao uso e ao exercício da lógica nas discussões. Como sempre, a prática antecedeu à teoria, o uso antecipou-se aos preceitos. Coube a Aristóteles a idéia e a formulação das regras da nova arte, ou seja, a constituição da Lógica. Daí ser o "Príncipe dos Peripatéticos" considerado como seu principal fundador. Se nas restantes disciplinas êle compartilha de autoridade com outros autores, na Lógica êle é único, é ímpar, exercendo verdadeiro monopólio intelectual (121).

João de Salisbury iniciou-se no estudo da dialética sob a direção de Abelardo. Prosseguiu os estudos com mestre Alberico e com Roberto de Melun. Em Chartres estudou com o "gramático" Guilherme de Conches durante três anos. Repassou, em seguida, tudo que havia estudado anteriormente sob os cuidados de Ricardo, o Bispo, e aprofundou mais as matérias do quadrívio, nas quais já fôra iniciado pelo alemão Hardewin. Reviu, também, a retórica que estudara com Teodorico de Chartres. Mais tarde, aprimorou o estudo dessa matéria com Pedro Helias. A fim de poder acudir às próprias necessidades, tornou-se preceptor de filhos de nobres, uma vez que era pobre, como confessa, não dispondo nem de amigos nem de

\footnotetext{
(121). - "... et qui alias disciplinas communes habet cum auctoribus suis, sed hanc sue fure vindicans, a possessione lllius exclusit caeteros". MET. PL 199, cl. 839 A.
} 
parentes que pudessem auxiliá-lo. As obrigações do magistério, as perguntas formuladas pelos alunos, compeliram o futuro autor do Metalogicus a recordar o que já aprendera. Para isso recorreu aos préstimos de mestre Adão da Ponte Pequena, homem muito inteligente, que se consagrava especialmente ao estudo de Aristóteles, mas que teve o defeito de complicar a lógica aristotélica com as teias inextricáveis de suas sutilezas (122).

Depois de lecionar durante três anos, Salisbury retornou a $\mathrm{Pa}$ ris onde estudou dialética e teologia com Gilberto Porretano. Quando êste foi nomeado bispo de Poitiers, passou a estudar teologia sucessivamente com Roberto Pullen e Simão de Poissy. Assim, transcorreram doze anos de afincados estudos. Salisbury quís, então, rever o cenário de suas primeiras labutas intelectuais no terreno das Artes, a fim de avaliar o seu progresso por comparação com o grau de discernimento que seus antigos colegas houvessem alcançado. E, ó surpresa e desencanto! Encontrou-os no mesmo ponto e da mesma maneira como os deixara; não haviam adiantado um palmo sequer e não tinham conseguido, em tanto tempo, acrescentar uma única proposição nova à solução dos antigos problemas. Aliás, é preciso reconhecer que haviam mudado realmente sob um aspecto: já não conheciam a moderação. Salisbury concluiu dessa experiência que, se a dialética é proveitosa para os outros estudos, torna-se estéril e pobre quando cultivada por si mesma, o que equivale a reconhecer seu caráter instrumental. Preciosa advertência para tantos cultores dos formalismos da lógica matemática hodierna.

Depois de relembrar seus anos de formação e antes de passar ao exame da questão dos Universais, o Saresberiense deixa escapar, entre muitas observações e pontos de vista, uma crítica aguda a certa mania dos mestres de então, e que constituía, a seu ver, um atentado didático aos jovens estudantes de lógica. Diz êle que tais mestres, amantes das sutilezas, multiplicam as afirmações e tratam a questão dos Universais, procurando aprofundar problemas que ainda não estão à altura de seus ouvintes e que deviam ser reservados para estudos mais avançados. O estudo inicial da lógica devia caracterizar-se, ao contrário, pela simplicidade, brevidade e facilidade da matéria. A tal estudo se poderia aplicar, de acôrdo com o espírito do que diz Salisbury, o conselho que São Tomás de Aquino deu a frei João: 
"procura penetrar no oceano do saber por pequenos riachos"
(123).

O grande problema filosófico que apaixonou os estudiosos da filosofia no século XII, e que acabou por dar a impressão de que o estudo dessa matéria se reduzia a tal problema, foi o dos Universais. A advertência de Porfírio, na Isagoge, a respeito da dificuldade dessa questão, que ele tratou de evitar; a repetição dessa advertência, feita por Boécio, eram de molde a constituir mais um chamariz que entrave para os curiosos e árdegos cultores do Trívio no século XII.

João de Salisbury proporciona, no capítulo XVII do livro II do Metalógico, preciosas informações a respeito das opiniões em que se dividiam os mestres de sua época a propósito da questão dos Universais. Prantl faz ressalvas a essas informações (124). Seriam genéricas e, em boa parte, puramente de memória... Mas é preciso reconhecer o pêso do depoimento do Saresberiense, uma vez que êle foi protagonista dessa luta de idéias; êle conviveu com os defensores das opiniões que descreve, e tudo, em sua obra, indica a clarividência de seu espírrito, o seu bom senso, a sua sagacidade.

Ao mesmo tempo em que vamos examinar as idéias, daqueles que Salisbury denominava "modernos", a respeito dos gêneros e das espécies, teremos a oportunidade de conhecer o pensamento do autor sôbre a questão. Êle começa por observar que os professôres teimavam em dilucidar a questão dos Universais de maneira contrária à intenção de Aristóteles, contra mentem auctoris, em cursos de lógica para principiantes. Em seguida, êle apresenta uma resenha das opiniões em voga sôbre tal assunto. Uns sustentam que os universais não passam de palavras, de sons, opinião essa, diz êle, que, com seu autor Roscelino, já teria caído no esquecimento. Outros acham que os Universais são sermones, isto é, têrmos significativos, palavras-conceitos. Assim Abaelardus noster, o Peripatético do Pallet. Muitos de seus discípulos, entretanto, afirmavam ser absurdo usar uma coisa com $_{\mathrm{O}}$ predicado de outra, ainda que Aristóteles fôsse o autor dessa monstruosidade.

Para um terceiro, baseado em Cícero e Boécio, que pretendem seguir Aristóteles, gêneros e especécies devem ser entendidos como

(123). - "Ut per rivulos, non statim in mare, eligas introire, quia per faclliora ad difficiliora oportet devenire". S. Thomae Aquinatis, EPISTOLA EXHORTATORIA de MODO STUDENDI ad Fratrem Joannem in OPUSCULA THEOLOGICA, v. I, pág. 451 .

(124). - "Wenn wir dem Johannes von Salesbury, welcher zwar häufig bloss allgemeinen Eindrücken und vieles nur aus dem Gedächtniss niederschrieb (s. unten Anm. 536), vollständig vertrauen dürfen". Prantl GÉSCHICHTE der LOGIK im ABENDLANDE, II, XIV, Reichere Bewegung. 
intellectus, ou sejam, noções. Para os adeptos desta opinião, noção é o conhecimento anterior à percepção da forma de qualquer coisa e que precisa de explicação, ou ainda:

"a noção é um certo significado (intellectus), uma simples concepção mental".

Por isso, distorcem tudo quanto se escreveu sôbre tal assunto, a fim de que o intellectus ou noção inclua a universalidade-dos universais. Quanto aos que se apegam à opinião de que os Universais são coisas, é preciso estabelecer distinções. Um, por exemplo, argumenta que, se cada coisa existente é singular, então, o Universal é numèricamente um ou não existente. Mas desde que é impossível que os sêres substanciais, as essências, não existam se aquelas coisas para as quais são substanciais existem, então os Universais devem ser essencialmente unos com as coisas particulares. Outros, ainda, de acordo com Valter de Mortagne, distinguem vários estados (status) de existência e dizem que Platão é um indivíduo, enquanto Platão; é espécie, enquanto homem; é um gênero subalterno, enquanto animal, e é gênero supremo (generalissimum), enquanto substância . Esta opinião teve defensores, mas desde pouco, diz Salisbury, ninguém mais a defende.

Valter de Mortagne admite a teoria das idéias, rivalizando com Platão e imitando Bernardo de Chartres, e afirma que gênero e espécie não passam de "idéias". Esste último, juntamente com seus seguiảores, tentou conciliar Platão com Aristóteles, mas, diz Salisbury,

\footnotetext{
"acho que chegaram tarde e trabalharam em vão para reconciliar. mortos que, em vida, nunca se entenderam".
}

Outro a tentar explicar Aristóteles foi Gilberto, bispo de Poitiers, atribuindo a universalidade às "formas nativas", que se identificariam com os universais (in earum conformitate laborat). A forma nativa é "um exemplo do original" que não está na mente divina, mas é inerente às coisas criadas. Ela é sensível nas coisas sensíveis, porém é concebida pela mente como não-sensível; é singular nos indivíduos, mas universal em todos os pertencentes à mesma espécie.

Outra opinião é a de Joscelino, bispo de Soissons, que atribui universalidade à coleção das coisas (rebus in unum collectis), negando-a a cada uma individualmente.

Alguém, diz Salisbury irônicamente, que não domina suficientemente o latim, apela para um barbarismo (ad subsidium novae 
linguae), considerando os universais, gêneros e espécies, como maneries das coisas (125). Não vejo, diz Salisbury o que isso possa significar, a não ser que se trate da coleção de coisas, conforme Joscelino, ou de uma entidade universal, à qual, entretanto, não convém a designação de maneries. Seja como fôr, a verdade é que por tal nome poder-se-iam tomar essas duas interpretações, pois maneries pode designar o número ou o estado (status) de coisas no qual o ser permanece invariável.

Finalmente há os que reduzem gêneros e espécies aos estados (status) das coisas.

Num passo do Policraticus, Salisbury enuncia as opiniões que reduzem os universais a sonoridade verbais (voces), a têrmos significativos (sermones), a estados e noções (intellectus), acrescentando, entretanto, uma quinta opinião que não aparece no Metalogicus, ou seja, a dos que, à semelhança dos matemáticos, consideram os universais como formas abstratas (126).

Passando a examinar o lídimo pensamento de Aristóteles a respeito dos Universais, Salisbury expõe também seu próprio ponto de vista, alinhando-se decididamente ao lado do Estagirita em oposição a Platão. Esse exame da doutrina aristotélica foi encaminhado pela observação do autor sôbre o mau hábito de certos mestres da época que, dizendo-se seguidores de Aristóteles, ou ensinavam em nome dêste doutrinas de Platão ou transmitiam falsas opiniões em nome de ambos.

(125) . - No texto de Webb lê-se "maneries"; no de Migne "materies". Cf. Prantl, idem, pág. 120 , nota 69 .

(126) . - "In his aetatem teiere, nihil agentis, et frustra laborantis est. Nebulae siquidem sunt rerum fugacium, et cum quaeruntur avidius, citius evanescunt. Expediunt hanc auctores multis modis, varisque sermonibus; et dum indifferenter verbis usi sunt, varias opiniones invenire visi sunt, et litigiosis hominibus multam contendendi materiam reliquerunt. Inde est quod sensibilibus, aliisque singularibus apprehensis, guoniam haec sola veraciter esse dicuntur, et in diversos status subveht, pro quorum ratione in ipsis singularibus specialissima generalissimaque constituit. Sunt qui more mathematicorum, formas abstrahunt, et ad illas quidryid de universalibus dicitur, referunt. Alii discutiunt intellectus, et eus universalium nominibus ccnseri confirmant. Fuerunt et qui voces ipsas genera dicerent esse et species; sed eorum jam explosa sententia est, et facile cum auctore suo evanuit. Sunt tamen adhur qui deprehendunour in vestigiis eorum, licet erubescant auctorem vel sntentiam profiteri, solis nominibus inhaerentes, quod rebus et intellectibus subtrahunt, sermonibus ascribunt.

Magno se judice quisque tuetur

et ex verbis austorum, qui indifferenter nomina pro rebus, vel res pro nominibus posuerunt, suam astruit sententiam vel errorem. Oriuntix hinc magna seminaria jurgiorum, et colligit quisq de quo suam possit haeresin confirmare". POLYCRATICUS, PL T. 199, cl. 664 D/665 A. 
Segundo Aristóteles, os gêneros e as espécies não existem; são apenas entendidos (127). Afasta-se dêle quem admite que os universais existem por si ou quem acolhe as opiniões que os reduzem a sonoridade verbais, a têrmos significativos, a coisas sensíveis, a idéias, a formas nativas, a naturezas e coleções. Quem admite que os universais têm existência objetiva contradiz Aristóteles (128).

Salisbury passa em seguida a discutir o significado dos universais. Ainda que não exista homem senão individualizado como êste ou aquêle, contudo pode se entender e conceber o "homem", de tal modo que com tal representação não se faça referência a êste ou àquêle homem concreto. Os gêneros e as espécies são concebidos pelo intelecto abstrativo, que apreende puros conceitos e os quais na realidade concreta não existem separados das coisas sensíveis (129). A razão, considerando a semelhança substancial de coisas diferentes, apreende os gêneros e as espécies (130). Êstes, por conseguinte, não são formas estranhas aos sêres individuais, mas representações de coisas naturais e atuais, que brilham para o intelecto como imagens de coisas concretas refletidas no espêlho da pureza natural da alma (131).

À semelhança das definições em gramática, que são exemplares distintos dos exemplos concretos, certos exemplares são concebidos mentalmente de acôrdo com os exemplos formados pela natureza, que os apresentou aos sentidos. Tais exemplares são abstrações, imagens e sombras das coisas existentes, segundo Aristóteles. A quem

\footnotetext{
(127). - "Porro hic, geneia et species non esse, sed intelligi tantum asseruic' METALOGICUS, PL 199, Lib. II, cap. 20, cl. 877 B.

(128). - "Quare ab Aristotele recedendum est, concedendo ut universalia äint, aut refragandum opinionibus, quae eadem vocibus, sermonibus, serisibiltbus rebus, ideis, formis, naturis, collectionibus aggregant, cum singula horum esse non ciubitentur. Qui autem ea esse statuit, Aristoteli adversatur'. MET., Lib. II, cap. $20, \mathrm{cl} .877 \mathrm{C}$.

(129). - "Licet enim esse nequeat homo, qui non sit iste, vel alius hom', intelligi autem potest et significari: ita quod nec intelligatur, nec significetur iste, vel alius. Ergo ad significationem incomplexorum, per abstrahentem intellectum genera concipiantur, et species; quae tame:1, si quis in re um natura, dilfgentius a sensibilibus remota, quaerat, niniI aget et frustra laborabit; nihil enim tale natura peperit". MET, Fr, 199, Lib. II, cap. 20, cl. 878 A.

(130) . - "Rafio autem ea deprehendit, substantialem similitudinem rerum differentium pertractans apud se..." MET., PL 199, Lib. II, cap. 20, cl. 873 B.

(131). - "Sunt itaque genera $\epsilon$ species non quidem res a singularibus actu et natualiter alienae, sed quaedam naturalium et actualium phantasiae renitentes intellectui, de similitudine actualium, tamquam in speculo nativac puritatis ipsius animae... hoc est rerum imagines in mente apparentes". MET., FL 199, Lib. II, cap. 20, cl. 878 B.
} 
tenta apreendê-los como coisas reais, escapam como sonhos. São formas aparentes (monstra), que só se revelam ao intelecto (132).

Para Salisbury é indubitável que nada existe como universal que não se encontre nos sêres individuais. O universal não é uma entidade que exista separadamente das coisas singulares, a não ser no sentido em que são verdadeiros ou semelhantes os significados dos têrmos complexos (133). Para Aristóteles os universais só existem enquanto são entendidos, e nenhum ser atual é universal (134). Gêneros e espécies não dizem apenas como as coisas são, mas indicam sua natureza, a espécie a que pertencem; não são meras concepções do que é, mas também de como alguma coisa é o que é (135). Gêneros e espécies, como já se observou, são exemplares das coisas individuais; isso, porém, se deve entender como recurso didático e não como indicação de que sejam as causas das coisas singulares (136).

Quanto à concepção platônica dos Universais, Salisbury declara que não a combate nem a defende, mas prefere manter-se em atitude de indiferença, sem a qual não é possível captar o pensamento do autor que se estuda (137). Afirma,ainda, que não adota a teoria das idéias, apesar de Platão contar com grande número de seguidores, como Agostinho e "vários contemporâneos nossos". Neste as-

(132). - “. sic quaedam exemplaria concipiuntur in mente, quorum exempla natura formavit, et sensibus objecit. Illa itaque exenplaria, cogitabilia quidem sunt, et sunt quasi phantasiae et umbrae existentium, secundum Aristotelem; quas si quis apprehendere nititur per existentiam, quam habent a singularibus separatam, velut somnia eiabuntur. Monstra enim sunt, et soli intellectui patent". MET., PL 199, Lib. II, cap. 20, cl. $878 \mathrm{C}$.

(133). - "Nihil autem universale est, nisi quod in singularibus invenitur. Scorsum tamen a multis quaesitum est, sed tandem nihll invenerunt omnes in manibus suis: quoniam seorsum a singularibus, niliil est, nisi forte qualia sunt vera, aut similia complexorum significata sermonum". MET., Lib. Ir, cap. 20, cl. 879 C.

(134). - "Ergo duntaxat intelliguntur, secundum Aristotelem, universalia; sed in actu rerum nihil est quod sit universale". $M E T$., Lib. II, cap. 20 , cl. $885 \mathrm{~A}$.

(135) - "Ergo, ex sententia Aristotelis, genera et species, non omnino quid sit, sed quale quid quodammodo concipiuntur". MET., PL 199, Lib. II, cap. 20, cl. $885 \mathrm{C}$.

(136). -- "Sunt itaque geneia et species exemplaria singulorum; sed hoc quidem magis ad rationem doctrinae (si Aristoteles verus est) quam ad causam. essentiae; procedit et haec monstruosa (ut licentius loquar) figmentorum speculatio usque ad ventilationem singularium". MET., PL 199 , Lib. II, cap. 20, cl. $886 \mathrm{C}$.

(127). - "Ego quicem opinionem hanc vehementer nec impugno, nem propugno; nec enim multum referre aibitror, ob hoc quod illam amplector indifferentiam in vicissitudine sermonum, sine qua non credo quempiam ad mentem auctorum fideliter pervenire'. MET. PL 199, Lib. II, cap. 20, cl. $886 \mathrm{D}$. 
sunto, diz êle, seguimos a doutrina de Aristóteles, o Príncipe dos Peripatéticos (138). Salisbury reconhece que é difícil escolher entre as opiniões de Platão e de Aristóteles nessa questão dos Universais, o que o próprio Boécio reconheceu. Mas, finaliza, quem ler as obras de Aristóteles haverá de reconhecer ter sido êle quem mais aprofundou o problema (139).

De tudo que aí fica exposto infere-se que João de Salisbury aproveitou bem do estudo de Aristóteles, assim como da argúcia e do espírito crítico de mestres como Abelardo. A respeito do problema dos Universais, deixou-nos informações valiosas sôbre o que leu e ouviu, e soube frisar muito bem que os conceitos universais não possuem existência objetiva e são estritamente conceitos que o intelecto abstrai dos sêres individuais e concretos.

Outro ponto a ressaltar é que, se êle opta pela solução aristotélica em tal questão, assim faz convicto de que Aristóteles foi quem mais aprofundou o problema e soube afirmar que os Universais existem apenas como formas abstratas e não como coisas objetivas; são entendidos como tais, mas não existem por si.

Salisbury sabe ser aristotélico sem servilismo, e formou opinião sôbre o assunto em tela depois de capacitar-se do que se dizia pró ou contra tal solução, informando-se dos vários pontos de vista existentes. Em suma, foi um espírito aberto para o livre exame das várias opiniões concernentes a êsse problema filosófico, tendo revelado espírito crítico e capacidade para propor uma solução própria e mostrar como chegou até ela.

Arguto observador das práticas escolares, soube tecer críticas aos mestres entaipados na lógica e que, desprovidos de senso didático, iniciavam seus cursos para adolescentes, examinando a questão dos Universais.

Outra faceta do aristotelismo saresberiense, e à qual vou acenar como fecho dêsse capítulo, diz respeito à receptividade de João de Salisbury às obras da Logica Nova, ou sejam, os tratados do

\footnotetext{
(138). - "Unde. licet Plato coetum philosophorum grandem, et tam Augustinum quam alios plures nostrorum, in statuendis ideis habeat assertores; ipsius tamen dogma in scrutinio unlversalium nequaquam sequimur; eo quod hic Peripateticorum principem Aristotelem, dogmatis hujus principem profitemur". MET, PL 199, Lib. II, cap. $20, \mathrm{cl}, 888 \mathrm{~B}$.

(139). - "Magnum quidem est, et quod Boetius in secundo commento super Porphyrium, minus arduum fatetur, tantorum virorum dijudicare sententias, sed el qui Peripateticorum libros aggreditur, magls Aristotelis sententia sequenda est; forte non quia verlor, sed plane quia his disciplinis magis accomoda est". MET. PL 199, Lib. II, cap. 20, cl. 888 C.
} 
Organon, que só se difundiram em latim durante o século XII: os Analíticos, os Tópicos e os Elencos Sofísticos, mercê das novas traduções empreendidas no sul da Itália e em Toledo. Já aludimos, páginas atrás, às viagens de Salisbury à Itália, onde se familiarizou com as obras que vieram a integrar a Logica Nova. Vejamos agora o que êle tem a dizer a propósito dos novos livros de Aristóteles, que importância thes concedeu e que virtudes nêles entreviu. Da leitura do Livro III do Metalógico a conclusão que se afigura irresistivel é que a obra mais séria, mais rica e mais importante do Organon é a dos Tópicos.

As observações do autor a respeito dos livros da Logica Nova encontram-se nos livros III e IV do Metalógico. A maior parte do Livro III é consagrada aos Tópicos, e o espaço concedido a essa obra, em relação ao que é proporcionado às outras, dá bem a medida do alto conceito em que a teve João de Salisbury. Este estabeleceu uma comparação entre as partes da aprendizagem gramatical e os livros em que se divide o Organon, na qual os Tópicos levam a parte do leão. O livro das Categorias, diz êle, é alfabético (elementarius), e o do Peri Hermeneias (De Interpretatione) é silábico, pois os elementos constitutivos do raciocínio que no livro das Categorias são apresentados separadamente como têrmos incomplexos, são reunidos, por sua vez, no livro Da Interpretação, como as letras se juntam para formar as sílabas, e estas são apresentadas combinadamente para designar o que é verdadeiro e o que é falso (140). Prossegue Salisbury, advertindo que, se o livro das Categorias é alfabético, e o da Interpretação é silábico, o dos Tópicos é de certa maneira verbal (dictionalis) (141). Continuando com sua analogia, observa finalmente, que, se o livro das Categorias é alfabético, o da Interpretação silábico, e os sete primeiros livros dos Tópicos são verbais, o oitavo constrói o raciocínio, constructorius est rationum (142).

\footnotetext{
(140). - "Liber Periermeniarum vel potius Periermenias, ratione proportionis syllabicus est, sicut praedicamentorum elementarius; nam elementa rationum, quae singulatim tradit in sermonibus imcomplexis, iste colligit et in modum syllabae comprehensa producit ad veri falsique significationem". MET. PL 199, cl. 899 C.

(141). - "Sicut autem elementarius est praedicamentorum, periermeniarum vero syllabicus, ita et topicorum liber, quodammodo dictionalis est". MET., PL 199, cl. 904 B.

(1.42) . -- "Ut autem praemissae simllitudinis sequamur proportionem, quemadmodum categoriarum elementarius, periermeniarum syllabicus, praemissi topici, dictionales libri sunt; sic topicorum octavus, constructorius est rationum, quarum elementa, vel loca, in praecedentibus monstrata sunt". $M E$ T., PL 199, cl. 910 B.
} 
Enaltecendo os livros que vieram a integrar a Logica Nova e a completar em tradução latina o Organon de Aristóteles, João de Salisbury proclama que o conteúdo da arte lógica cifra-se principalmente nos tratados dos Tópicos, dos Analíticos e das Refutaçóes ou Elencos Sofísticos (143).

Desde que se conheçam perfeitamente estas três obras e se esteja afeito ao seu manêjo, chega-se à conclusão de que o conhecimento dos Tópicos é o mais necessário, especialmente para aquêles que lidam com a questão da probabilidade. A ciência dos Tópicos é útil não só para o dialético e para o orador, como também para os que tratam da demonstração e para os que, envolvendo-se em discussões, se vêem às voltas com as falácias (144). Já que os Tópicos possuem utilidade tão evidente, confessa Salisbury, é para surpreender que nossos antecessores os tenham negligenciado a tal ponto, que a obra chegou a cair completamente, ou quase, em desuso. Em nossos dias, porém, as investigações de estudiosos diligentes arrancaram-na à morte, ou a despertaram do sono, para que ela pudesse descortinar o caminho da verdade aos que a procuram (145). O valor dêsse tratado é tamanho, que cada uma de suas palavras, nas regras e nos exemplos, pode ser proveitosamente aplicada não só à lógica, como também a todos os ramos do conhecimento (146). Salisbury destaca em seguida o alcance dos três primeiros livros dos Tópicos, cujo conhecimento é útil para o estudo da física e da ética, lamentando que seus predecessores tivessem negligenciado tal obra, privando-se, des-

(143) . - MET., PL 199, Lib. III, cap. V, cl. 902 A.

(144). - "Ipsum itaque quodammodo corpus artis deductis praeparatitis, principaliter consistit in tribus, scilicet topicorum, analyticorum, elenchorumque notitia: his enim perfecte cognitis, et habitu eorum per usum et exercitium roboratis, inventionis et judicii copia suffragabitur in omni facultate, tam demonstratori quam dialectico et sophistae. Porro in his maxime necessaria est, praecipue probabilitatem sectantibus, scientia topicorum quae, etsi inventionem principaliter instruat, judiciis tamen non mediocricer suffragatur. Et quamvis, ex opinione multorum, dialectico et oratori principaliter faciat, ipsam fere aequaliter proficere arbitror iis, qui versantur in gravitate demonstrationis, aut in fallacia et agone sophistico". MET., PL 199, cl. 902 B.

(145). - "Cum Itaque tam evidens sit utilitas topicorum, miror quare cum alis a majoribus tandiu intermissus sit Aristotelis liber, ut omnino, aut fere, in desuetudinem abierit, quando aetate nostra, diligentis ingenii pulsante studio, quasi a morte, vel a somno excitatus est, ut revocaret errantes, et viam veritatis quaerentibus aperiret". MET., PL 199, cl. $902 \mathrm{C}$.

(146). - "Singula verba ejus, tam in regulis quam in exemplis, non modo ad dialecticam, sed fere ad omnes proficiunt disciplinas". MET., PL 199, cl. $903 \mathrm{~A}$. 
sa maneira, dos benefícios já mencionados, assim como da sua agradável leitura (147) .

Tendo chegado em sua análise dos Tópicos ao sétimo livro, Salisbury observa que não escapará ao estudioso atento o fato de terem saído dessa obra os Tópicos de Cícero e de Boécio, e também as Divisões dêste último, obra de relêvo entre seus escritos de lógica devido à brevidade e à propriedade dos juízos (148).

A autor chega, por fim, ao oitavo livro dos Tópicos, que "constrói o raciocínio". Se fôr bem assimilada e corretamente observada, essa obra contribui mais para a ciência do raciocínio do que todos os livros de dialética usados nas escolas pelos mestres do seu tempo. Sem êste livro, as discussões dependeriam mais do acaso do que da arte (149). Ele tem o condão de despertar nos alunos certa astúcia para as justas do pensamento; é a principal fonte da eloqüência (150).

Passando a considerar os Analiticos, Salisbury observa que o Instrutor da Escola Peripatética - campidoctor itaque Peripateticae disciplinae - após assegurar recursos para a invenção dos argumentos, providenciou os meios para a análise científica do raciocínio. Daí a qualificação dos Analíicos no título do capítulo em foco como rationum examinatorius. A ciência que nêles se contém é tão proveitosa, que, desejar ser lógico sem ela, é cair no ridículo (151).

No capítulo $2^{\circ}$ do Livro IV encontra-se ligeira referência ao tradutor dos textos de que se servia Salisbury, traço que patenteia os

(147). - "Ex quo liquet, quantum haec disciplina physicae et ethicae prodest. Cum haec disciplinae particula, in appetendis et devitandis, et in omnibus denlque comparabilibus vigeat, plane hujus lata est commendatio, et male neglectus a prioribus, cum utllitate conspicua, et verborum gratia jucundus sit, et tam ethicae quam physicae plurimum prosit". MET., PL 199, cl. 905 C.

(148). - "Qui vero librum hunc diligentius perscrutatur, non modo Ciceronis et Boetii topicos ab his septem voluminibus erutos deprehendet, sed librum divisionum, qui compendio verborum, et elegantia sensuum, inter opera Boetil, quae ad logicam spectant, singularem gratiam nactus est". MET., PL. 199, cl. 909 A.

(149). - "Solus itaque versatur in praeceptis, ex quibus ars compaginatur, et plus confert ad scientiam disserendi, si memoriter habeatur in corde, et jugi exercitio versetur in opere, quam omnes fere libri dialecticae, quos moderni praeceptores nostri in scholis legere consueverant: nam sine eo, non disputatur arte, sed casu". MET., PL 199, cl. $910 \mathrm{C}$.

(150) . - "Quia ergo exercitatio dialecticae ad alterum est, pares, quos producit, et quos rationtbus munivit, et locis, sua docet arma tractare, et sermones potius conserere quam dexteras, et tanta cautela imbuit, ut totius eloquentiae praecepta hinc tracta principaliter, velut a primitivo fonte originis suae, manare perspicuum sit". MET., PL 199, cl. 910 C/910 D.

(151). - "Analyticorum quidem perutilis est scientia, et sine qua quisquis logicum profitetur, ridiculus est". MET., PL 199, cl. $916 \mathrm{D}$ in fine. 
laboriosos estudos a que se entregou nosso autor na Itália. Quando se lhe deparava alguma expressão não familiar, especialmente em se tratando de têrmo composto, o tradutor aconselhava: "análise", querendo dizer com isso que esperava uma explicação em têrmos equivalentes.

Em sua explanação sôbre os Primeiros Analiticos Salisbury adverte o leitor sôbre a importância dos silogismos modais para a correta interpretação da Escritura (152).

Os Segundos Analíticos ou Analíticos Posteriores, constituem, a seu ver, obra de rara sutileza, adiantando se poucos em seu conhecimento. A razão disso é que ela é consagrada à arte da demonstração, a forma mais árdua do raciocínio. O que o Saresberiense escreve nessa altura é muito esclarecedor a respeito dos estudos de sua época. Diz êle que essa arte estava então em desuso. Só a empregavam os matemáticos, e entre êles os geômetras. O estudo da geometria não era conhecido no seu meio, continua, embora fôsse muito difundido na região ibérica e nos confins da África, in tractu Hibero vel confinio Affrice. Os moradores dessas plagas recorriam muito à geometria que tomavam como instrumento da astronomia. Pode-se dizer o mesmo dos egípcios e dos povos da Arábia.

Outra séria dificuldade, que torna êsse livro mais complicado que os demais, provém das confusões e enganos perpetrados pelos copistas, e dos dislates dos tradutores (153). Repentindo Burgúndio de Pisa, afirma Salisbury ter sido a mestria na arte da demonstração que valeu a Aristóteles o título de "o Filósofo" por execelência (154).

Finalmente, refere-se o autor aos Elencos Sofisticos e, relutante, afirma que nenhum outro estudo poderia ser mais benéfico para a juventude, pois o sofista é um simulador de sabedoria, que aparenta ser o que não é. Em vão alguém se gloriaria de ser filósofo, sem co-

\footnotetext{
(152). - "Est enim modus, ut aiunt, quasi quidam medius habitus terminorum. Et profecto licet nullus modos omnes, unde modales dicuntur, singulatim enumerare sufficiat, quod quidem nec ars exigit, tamen magistri scholarum inde commodissime disputant, et, ut pace multitudinis loquar, Aristotele ipso commodius opinor. Utique quod sive ob verum modum, sive ob solam formam dicantur modales, earum, apud plurimos Scripturarum locos, necessaria est cognitio". MET., PL 199, cl. 918 C.

(153) . - "Ad haec, liber quo demonstrativa traditur disciplina, caeteris longe turbatior est, et transposiotione sermonum, trajectione litterarum, desuetudine exemplorum, quae a diversis disciplinis mutuata sunt. Et postremo quod non attingit auctorem, adeo scriptorum depravatus est vitio, ut fere quot capita, tota obstacula habeat. Ft bene quidem, ubi non sunt obstacula capitibus plura. Unde a plerisque, in interpretem difficultatis culpa refunditur, asserentibus, librum ad non recte translatum pervenisse". MET., PL 199, c1. 919 D/920 A.

(154). 一 MET., PL 199, Lib. IV, cap. 7, cl. 920 A.
} 
nhecer esta obra (155). O treino na refutação dos sofismas é exercício muito útil para assegurar a reta expressão do pensamento e as investigações de tôda a filosofia (156). O fruto dêsse exercício é a verdade e não a verbosidade.

Para encerrar êste capítulo, devo apenas observar que para um autor do século XII, como João Salisbury, ser aristotélico era, para início de conversa, conhecer as obras de Aristóteles, por meio de leitura atenta e crítica. Não poderia expor sua doutrina, nem discutí-la, quem não tivesse conhecimento direto das fontes. Grande lição para os que contraíram o vêzo de serem e se proclamarem aristotélicos, sem jamais se terem abeberado nas obras do Filósofo, contentando-se com esquemas e súmulas, úteis e cômodos, sem dúvida, mas que, com sua secura e brevidade não permitem acesso ao manancial daquele fecundo pensamento.

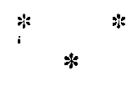

\section{BIBLIOGRAFIA .}

ABELARDO, PEDRO, Opera Theologica, Migne, Patrologia Latina, Tomo 178.

- Dialectica, First complete edition of the Parisian manuscript by L. M. De Rijk, Ph. D., Assen, Van Gorcum and Comp., 1956, 637 págs.

ADELARDO DE BATH, (Beiträge zur Geschichte der Philosophie des Mittelalters, Band IV, Heft I), Hans Wilner, Des Adelard von Bath Traktat De Eodem et Diverso, Münster, 1903, Druck und Verlag der Aschendorffschen Buchhandlung, 112 págs.

AGOSTINHO, SANTO, Bibliothèque Augustinienne, Oeuvres de Saint Augustin, 1e. série: Opuscules IV. Dialogues Philosophiques. I. Problèmes Fondamentaux.

- Contra Acadenicos - De Beata Vita-De Ordine, texte de l'Édition Bénédictine, Traduction, Introduction et Notes de R. Jolivet, Paris, Desclée, De Brouwer et Cie., 1950, 662 págs.

- XII. Retractationes (Les Revisions). Introduction, Traduction et Notes par Gustave Bardy, Paris, Desclé, De Brouwer et Cie,, 1950, 662 págs.

- Obras de San Agustin, Édicion bilingüe, Tomo XVI, De Civitate Dei (La Ciudad de Dios), Edición preparada por el Padre Fr. Jose Mora, O.S.A., Biblioteca de Autores Cristianos, Madrid, 1958, 1728 págs.

ALANO DE LILlE, Textes philosophiques du Moyen Age, Anticlaudianus, Texte critique avec une intreduction et tables publié par $\mathbf{R}$. Bossuat, Paris, Librairie Philosophique J. Vrin, 1955, 223 págs.

(155) . - "Frustra, sine hac, se quisque gloriabitur esse philosophum, cum nequeat cavere mendacium, aut alium deprehendere mentientem'. MET., PL 199 , cl. 929 B.

(156) . - "Unde et ad phrasim conciliandam, et totius philosophiae investigationes, sophisticae exercitatio plurimum prodest: ita tamen, ut veritas, non verbositas, sit hujus exercitii fructus'. $M E T$., PL 199, cl. 929 C. 
- Opera, Migne, Patrologia Latina, tomus 210.

- Études de Philosophie Médiévale, 52, Alain de Lille, Textes Inédits avec une Introduction sur sa vie et ses oeuvres par Marie-Thérèse d'Alverny, Paris, Librairie Philosophique J. Vrin, 1965, 382 págs.

ALFARABY'S, Philosophy of Plato and Aristotle, Translated with an Introduction by Muhsin Mahdi, The Free Press of Glencoe, 1962, 158 págs.

ALIGHIERI, DANTE, Obras Completas, Versión castellana de Nicolas Gonzales Ruiz, sobre la interpretación literal de Giovanni M. Bertini, Colaboración de José Luiz Gutierrez Garcia, Madrid, Biblioteca de Autores Cristianos, 1956, 1146 págs.

APUlEIO, Classiques Garnier, Apologie-Les Florides-Traités Philosophiques, Traduction nouvelle par Henri Clouard, Paris, Librairie Garnier Frères, s/data, 488 págs.

AQUINO, SÃO TOMÁS DE, Opuscula Theologica, Volumen I. De re dogmatica et morali, Cura et Studio P. Doct. Fr. Raymundi A. Verardo O. P., Taurini-Romae, edit. Marietti, 1954, 531 págs.

ARISTÓTELES, Union Académique Internationale. Corpus Philosophorum Medii Aevi Academiarum Consociatarum Auspiciis et consilio editum, Aristoteles Latinus IV 2, Analytica Posteriora, Translatio Anonyma, edidit Laurentius Minio-Paluello, Bruges-Paris, Desclée de Brouwer, 1953, 111 págs.

BERNARDO SILVESTRE, Bernardi Silvestris, De mundi universitate, Libri Duo sive Megacosmus ot Microcosmus, ed. Barach-Wrobel, Frankfurt a. M., Minerva G. M. B. H., 1964, 71 págs.

BERNARDO, SÃo, Sermones, Migne, Patrologia Latina, Tomo 183; Epistolae, PL 182, T. I: Oeuvres de Saint Bernard, traduites par M. Armand Ravelet, Tome deuxième: Lettres de Saint Bernard-Traités divers, Paris, Victor Plamé, Libraire-Éditeur, 1867, 526 págs.

BOÉCIO, ANICIO MÂNlio SEVERINO, Consolationis Philosophiae Libri $V$, Herausgegeben von Karl Büchner, 2. erneuerte Auflage, Heidelberg, Carl Winter Universitätsverlag, 1960, 122 págs. Boèce, La Consolation de la Philosophie, Traduction nouvelle avec une Introduction et des Notes par Aristide Bocognano, Paris, Librairie Garnier Grères, s/data, 281 págs.

BOYANCÉ M: P., Le Platonisme à Rome. Platon et Ciceron in Congrès de Tours et Poitiers, 3-9 september 1953. Actes du Congrès, Paris, Société d'Édition "Les Belles Lettres", 1954, 422 págs. Cf. pág. 266-285.

BOYER S. J., CHARLES, Christianisme et Néoplatonisme dans la formation de Saint Augustin, Romae, Officium Libri Catholici, 1953, 211 págs.

BREHIER ÉMILE, Histoire de la Philosophie, T. I, L'Antiquité et le Moyen Age -2- Période Héllenistique et Romaine, Paris, Presses Universitaires de France, 1955, pág. 261-527.

CHALCIDII, Commentarius in Timaeum Platonis in Mullachius, Fragmenta Philosophonim Graecorum, Volumen II, Parisiis, Editore Ambrosio Firmin-Didot, 1865; 438 págs.

CHENU M.-D, O. P., La Théologie au Douzième Siècle, Paris, Librairie Philosophique J. Vrin, 1957, 413 págs.

CLEMENTE DE ALEXANDRIA, Sources Chrétiennes, Les Stromates, Stromate I, Paris, Éditions du Cerf, 1951, 180 págs. 
- Le Protreptique, 2e. édition, Paris, Editions du Cerf, 1949, 215 págs.

COURCELLE PIERRE, Faculté des Lettres de l'Université de Paris, Les Lettres Grecques en Occident de Macrobe a Cassiodore, Paris E. De Boccard, Éditeur, 1943, 440 págs.; Recherches sur les Confessions de Saint Augustin, Paris, E. De Boccard, Éditeur, 1950, 299 págs.

CROUZEL HENRI, Origène et la Philosophie, Paris, Aubier, 1962, 238 págs.

DAL PRA MARIO, Giovanni di Salisbury, Milano, Fratelli Bocca Editori, 1951, 166 págs.

D'ALVERNY M. TH., Notes sur les traductions médiévales des ceuvres philosophiques d'Avicenne, in Archives d'Histoire Doctrinale et Littéraire du Moyen Age, T. 18, 1952, pág. 337-358, Paris, Librairie Philosophique J. Vrin; Avicenna Latinus, in Archives d'Histoire Doctrinale et Littéraire du Moyen Age, T. 28, pág. 281-316, Paris, 1962, Librairie Philosophique $\mathrm{J}$. Vrin.

ERIUGGENA JOÃO ESCOTO, De Divisione Naturae, Migne, Patrologia Latina, Tomo 122 .

FRAILE FR. GUILLERMO, O. P., Historia de la Filosofia, I, Grecia y Roma, Madrid, Biblioteca de Autores Cristianos, 1956, 839 págs.

GANDILLAC MAURICE DE, Le Platonisme au XIle et au XIII siècles, in Association Budé, Congrès de Tours et Poitiers, 3-9 september 1953. Actes $d u$ Congrès, Paris, Société d'Édition "Les Belles Lettres", 1954, 422 págs. Cf. pág. 266-285. La Sagesse de Plotin, Paris, Librairie Hachette, 1952, 207 págs.

GARIN EUGENIO, Quaderni li Letteratura e d'Arte raccolti da Guiseppe de Robertis, Studi sul Platonismo Medievale, Firenze, Felice Le Monier, 1958, 219 págs.

GHELliNCK, J. DE, S. J., Museum Lessianum-Section Historique, N's 4-5, L'Essor de la Littérature Latine au XIIe Siècle, 2e. édition, Bruxelles-Bruges-Paris, Desclée de Brouwer, 584 págs.

GILSON ETIENNE, La Philosophie au Moyen Age, Paris, Payot, 1947, 782 págs. La Cosmogonie de Bernardus Silvestris in Archives d'Histoire Doctrinale et Littéraire du Moyen Age, T. III, 1928, Paris, Librairie Philosophique J. Vrin, págs. 5-24.

GODOFREDO DE SÃo VITOR, Analecta Medievalia Namurcensia, Fons Philosophiae,-Texte publié et anneté par Pierre Michaud-Quentin, Namur, Editions Godenne, 1956, 68 págs.

GOICHON A.-M., La Philosophie d'Avicenne et son influence en Europe Médiévale, deuxième édition revue, corrigée et augmentée, Paris, Adrien-Maisonneuve, 1951, 137 págs.

GRABMANN MARTIN, Geschichte der Scholastichen Methode, Erster Band, Graz, Akademische Druck-U. Verlangsanstalt, 1957, 354 págs. (Obra em 2 volumes). Aristoteles im zwoelften Jahrhundert in Mediaeval Studies, Volume XII, 1950, Pontifical Institute of Mediaeval Studies, Toronto, Canada, págs. 123-162.

GREGóRIO NAZIANZENO, Les Grands Ecrivains Chrétiens, Grégoire de $\mathrm{Na}$ zianze, Les Discours Théologiques, traduits par Paul Gallay, Lyon-Paris, Emmanuel Vitte-Éditeur, 1942, 222 págs. 
HASKINS CHARLES HOMER, Studies in the history of Mediaeval Science, New York, Frederick Ungar Publishing Co., 1960, 411 págs.

HUGO DE SÃO VITOR, Adnotationes elucidatoriae in Pentateuchon, Migne, Patrologia Latina, tomo 175.

ISAAC J., O. P., Le Peri Hermeneias en Occident de Boèce a Saint Thomas. Histoire littéraire d'un Traité d'Aristote, Paris, Librairie Philosophique J. Vrin, 1953, 189 págs.

JUSTINO SÃO, Apologías y Diálogo con Trifón in Daniel Ruiz Bueno, Padres Apologistas Griegos, Madrid, Biblioteca de Autores Cristianos, 1954, 1006 págs.

LANDGRAF ARTUR MICHAEL, Introducción a lx historia de la literatura teológica de la escolástica incipiente desde el punto de vista de formación de las escuelas, Barcelona, Editorial Herder, 1965, 253 págs.

LE BLOND JEAN-MARIE, Les Conversions de Saint Augustin, Paris, Aub:er, 1950, 321 págs.

MACRóBIO, Commentarius ex Cicerone in Somnium Scipionis in Collection des Auteurs Latins publiée sous la direction de M. Nisard, Macrobe, Varron, Pomponius Mela, Texto e Tradução francêsa, Paris, Librairie de Firmin-Didot et Cie., 1883, 709 págs.

MANITIUS MAX, Handbuch der Altertumswissenschaft. Neunte Abteilung, .zweiter Teil, dritter Band, Geschichte der Lateinischen Literatur des Mittelalters. Vom Ausbruch des Kirchenstreites bis zum Ende Zwölften Jahrhunderts, München, C. H. Beck'sche Verlagsbuchhandlung, 1931, 1165 págs.

MOREAU JOSEPH, L'ime du monde de Platon aux Stoiciens, Hildesheim, Georg Olms Verlagsbuchhandlung, 1965, 200 págs.

MUNK S., Melanges de Philosophie juive et arabe, Nouvelle édition, Paris, Librairie philosophique J. Vrin, 1955, 536 págs.

ORÍGEnES, Contra Celsum, Migne, Patrologia Grega, tomo XI, t. primus; Peri Archon ou De principiis, ibidem.

PLATÃo, Oeuvres Complètes, Tome $\mathrm{X}$, Timée-Critias, Texte établi et traduit par Albert Rivaud, quatrième tirage revu et corrigé, Paris, Société d'Édition "Les Belles Lettres", 1963, 274 págs.

PLOTINo, Ennéades, Texte établi et traduit par Émile Bréhier, deuxième édition, Paris, Société d'Édition "Les Belles Lettres", 1954, 7 volumes; Museum Lessianum Series Philosophica XXXIII, Plotini Opera, Tomus I, Porphyrii Vita Plotini-Enneades I-III, Ediderunt Paul Henry et Hans-Rudolf Schwyzer, Paris, Desclée de Brouwer et Cie, Bruxelles, L'èdition Universelle, S. A., 1951, 417 págs.

PRANTL C., Geschichte der Logik im Abendlande, zweiter Band, Graz-Austria, Akademische Druck-U. Verlagsanstalt, 1955, 403 págs.

RAND EDWARD KENNARD, Founders of the Middle Ages, New York, Dover Publications Inc., 1957, 365 págs.

SALISBURY JOÃO DE, Polycraticus, Metalogicus, Entheticus, Migne, Patrologia Latina, tomo 199; The Metalogicon of John of Salisbury, A Twelfthcentury defense of the verbal and logical arts of the trivium. Translated with an Introduction and Notes by Daniel D. McGarry, Berkeley and Los Angeles, University of California Press, 1962, 305 págs. 
SCHEDLER, Die Philosophic des Macrobius in Beiträge zur Geschichte der Philosophic des Mittelalters, Band III, Heft 1, Münster, i. W., 1916.

SENECA, Lettres a Lucilizs, Texte établi, traduit et annoté par François et Pierre Richard, Paris, Classiques Garnier, 3 volumes, 1945, 1954, 1955.

TALAMO SALVATORE, L'Aristotelismo della Scolastica nella storia della Filosofia. Studi oritici. Terza edizione notevolmente accresciuta, Siena, Tipografia Edit. S. Bernardino, 1881, 510 págs.

TERTULLIANI Q. S., De praescriptione haereticorum, in Corpus Christianorum, Series Latina, I. Tertulliani Opera, Pars I, Turnholti, Typographi Brepols Editores Pontificis, 1954, 726 págs.

ÜEBERWEGS FRIEDRICH, Grundriss der Geschichte der Philosophie, Zweiter Teil, Dr. Bernhard Geyer, Die Patristische und Scholastische Philosophic, 13. Auflage, Basel, Stuttgart, Benno Schwabe und. Co. Verlag, 1958, 826 págs.

VAN STEENBERGHEN, Les Philosophes Belges, Textes et Études, Tome XIII, Siger de Brabant d'après ses oeuvres inédites, Second volume, Siger dans l'histoire de l'Aristotélisme, Louvain, Éditions de l'Institut Supérieur de Philosophie, 1942, págs. 357-759.

VANNI-ROVIGHI SOFIA, La Filosofia nel secolo XII, Appunti delle lezioni di

Storia della filosofia medioevale 1957-1958, Texto mimeografado "pro manuscripto", Universidade do Sagrado Coração, Milão, 122 págs.

VIVES JUAN LUIS, Obras Completas, Primera traslación castellana integra y directa, comentarios, notas y un ensayo bibliografico por Lorenzo Riber, Tomo segundo, Madrid, M. Aguilar Editor, 1948, 1.803 págs.

WHITEHEAD A. N., Coleção "A Marcha do Tempo", vol. 10, A Ciência e o Mitndo Moderno, tradução de Aires da Mata Machado Filho, 2a. edição, São Paulo, Editôra Brasiliense Limitada, 1951, 232 págs.

WILlelmuS DE CONCHIS, De Philosophia Mundi Migne, Patrologia Latina, tomo 172 .

- Glosae super Platonem. Texte critique avec Introduction, Notes et Tables par Édouard Jeauneau, Paris, Vrin, 1965, 358 págs. 